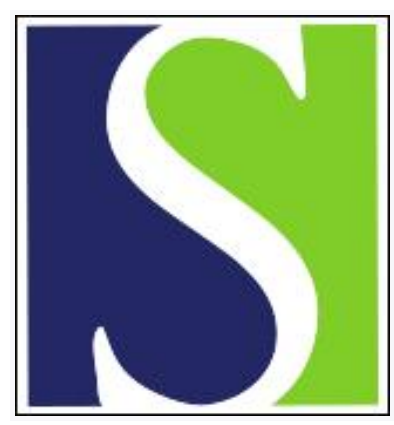

Scand J Work Environ Health 2006;32(5):359-367

https://doi.org/10.5271/sjweh.1031

Issue date: 31 Oct 2006

\title{
Time to pregnancy among female greenhouse workers
}

by Bretveld R, Zielhuis GA, Roeleveld N

Affiliation: Department of Epidemiology and Biostatistics (HP 133), Radboud University Nijmegen Medical Centre, PO Box 9101, 6500 HB Nijmegen, The Netherlands. R.Bretveld@epib.umcn.nl

Refers to the following texts of the Journal: 2003;29(2):85-93 2000;26(2):131-136 1999;25 suppl 1:49-61

Key terms: fertility; greenhouse worker; pesticide; subfertility; time to pregnancy; woman

This article in PubMed: www.ncbi.nlm.nih.gov/pubmed/17091203

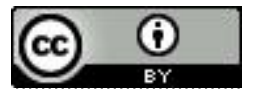




\title{
Time to pregnancy among female greenhouse workers
}

\author{
by Reini Bretveld, PhD, ${ }^{1}$ Gerhard A Zielhuis, PhD, ${ }^{1}$ Nel Roeleveld, PhD ${ }^{1}$
}

\author{
Bretveld R, Zielhuis GA, Roeleveld N. Time-to-pregnancy among female greenhouse workers. Scand J Work \\ Environ Health 2006;32(5):359-367.
}

Objectives Female greenhouse workers, who constitute a major occupational group exposed to pesticides at
childbearing age, were studied to measure the effects of pesticide exposure on time to pregnancy.
Methods Data were collected through postal questionnaires with detailed questions on time to pregnancy,
lifestyle factors (eg, smoking habits, coffee and alcohol consumption), and worktasks (eg, application of
pesticides, re-entry activities, and workhours) of the respondents and their partners in a 6-month period prior to
conception of the most recent pregnancy. The relation between time to pregnancy and exposure to pesticides
among 398 female greenhouse workers and 524 referents was studied in a Cox's proportional hazards model.
Results The crude fecundability ratio for female greenhouse workers versus the reference group was 1.18
[95\% confidence interval (95\% CI) $1.03-1.35$ ], but correction for confounding changed the fecundability ratio
to 1.11 (95\% CI 0.96-1.29). An evaluation of specific biases for time-to-pregnancy studies showed that these
results were biased by the reproductively unhealthy worker effect. Restricting the analyses to full-time workers
or first pregnancies only resulted in an adjusted fecundability ratio of 0.89 (95\% CI $0.67-1.19$ ) and 0.90 (95\% CI
0.62-1.32), respectively. Among the primigravidous greenhouse workers, an association was observed between
prolonged time to pregnancy and gathering flowers (fecundability ratio $0.46,95 \%$ CI 0.18-1.19). Conclusions This study may offer some evidence for the hypothesis of adverse effects of pesticide exposure on time to pregnancy, but more research is needed to elucidate these effects.

Key terms fertility; pesticide; subfertility; woman; worker.

Greenhouse and other agricultural workers are exposed to a large variety of pesticides, some of which may have endocrine disrupting properties or may affect human reproduction through other mechanisms (1-3). Although many animal studies have been performed on the reproductive toxicity of pesticides (1,3-6) and pregnancy outcome has been evaluated in several human studies (7-15), effects on human fertility have only recently been considered (16-26). For many pesticides, no information is available, and the majority of epidemiologic studies to date pertain to pesticides that are no longer used. Several studies investigated male workers only (16-19), while the results from a study in Finland indicated reduced fertility among wives of Finnish greenhouse workers exposed to pesticides (20).

In most agricultural settings, men are directly exposed to pesticides through the spraying of crops. Therefore, health effects are more often investigated among male workers than among female agricultural workers. However, female greenhouse workers constitute a ma- jor occupational group of workers who experience pesticide exposure at childbearing age. Usually, they are not directly exposed to pesticides but, instead, are indirectly exposed through re-entry (eg, while gathering or bunching flowers) or through take-home exposure by their husbands. Despite this exposure, few data on humans are available regarding fertility among female greenhouse workers $(21,22)$. Abell et al (21) did not observe a reduced overall fecundability among Danish women working in flower greenhouses, but spraying of pesticides and frequent manual contact with plants without gloves were associated with prolonged time to pregnancy (21). In Colombia, prolonged time to pregnancy was observed for women working in flower production companies where pesticides are frequently used (22). No consistent pattern of associations was found for a health study among farm families in Canada, but some specific pesticides were tentatively associated with reduced fecundability (23). In a study among clients of an infertility clinic in the United States, it appeared to be three

1 Department of Epidemiology and Biostatistics, Radboud University Nijmegen Medical Centre, Nijmegen, The Netherlands.

Reprint requests to: Dr R Bretveld, Department of Epidemiology and Biostatistics (HP 133), Radboud University Nijmegen Medical Centre, PO Box 9101, 6500 HB Nijmegen, The Netherlands. [E-mail: R.Bretveld@epib.umcn.nl] 
times more likely for infertile women than for fertile women to have ever been exposed to pesticides and nine times more likely to have ever worked in agriculture (24, 25). In a similar study, no correlations were found between infertility and self-reported overall pesticide exposure, working in the agricultural sector, or living on a farm, but an association was found when exposure to herbicides only was considered (26).

Time to pregnancy was first reported by Baird et al $(27,28)$ as a good measure for estimating fecundability. It provides an estimate of the per cycle probability of conceiving a clinically detectable pregnancy. An increase in time to pregnancy can indicate reproductive loss at any of several different stages, including gametogenesis, the transport of gametes in both male and female reproductive tracts, fertilization, migration of the zygote to the uterus, implantation, and early survival of the conceptus. Pesticides may disrupt the female hormonal balance and cause any of these effects, which are probably reversible. Therefore, time to pregnancy may be prolonged among women exposed to pesticides and thus indicate reduced fertility but not complete sterility. Time-to-pregnancy studies among women exposed to pesticides thus seem suitable for detecting adverse effects of pesticides on fertility.

Currently, there is not enough evidence to confirm or refute the hypothesis that female greenhouse workers have a prolonged time to pregnancy due to pesticide exposure. Therefore, a large retrospective cohort study on time to pregnancy was performed among female greenhouse workers in the Netherlands, where vast quantities of vegetables and flowers are produced. We focused on flower greenhouses, where large amounts of pesticides, such as abamectine, imidacloprid, methiocarb, deltamethrin, and pirimicarb (29), are used and many tasks require intensive contact with plants that precludes effective personal protection through the use of gloves.

\section{Study population and methods}

\section{Study population}

We used two different approaches to obtain the study population. From the database of a major trade union, which registers information about a variety of Dutch workers, we identified 604 female greenhouse workers and a random sample of 949 female cleaners of reproductive age (born in 1956-1979) in 2002. In addition, we obtained addresses of 2414 greenhouse owners through the national database of an agricultural marketing company. These owners were born in 1950-1979, or their date of birth was unknown. For the reference group, addresses of 4691 shopkeepers and market stallholders were obtained through the Chamber of Commerce. We only selected companies in which exposure to pesticides or other reproductive toxicants was unlikely (eg, builder's merchants and shops for household goods). The reference group of cleaners, retail shopkeepers, and market stallholders was chosen because of the assumed comparability with greenhouse workers and owners with respect to educational level, socioeconomic status, and work conditions, such as standing and carrying heavy loads.

\section{Data collection}

The 1553 women selected through the trade union database were sent an introductory letter, an information leaflet, and a self-administered questionnaire by mail. To the 7105 addresses obtained through the marketing company and the Chamber of Commerce, a mailing was sent that contained an introductory letter, an information leaflet, and a self-administered questionnaire for the owner of the company, plus the same items for the partner of the owner if he or she worked in the same company. If not, we asked the owner to give the extra questionnaire plus information leaflet to an employee of the opposite gender. We also asked the owners for the addresses of employees in the company so that we could send them questionnaires as well. Alternatively, the owners could choose to distribute questionnaires personally to their employees. To increase the response rates, we sent reminders after 2 and 6 weeks. To avoid selective nonresponse and information bias, the study was presented to the potential participants as a general study on work, lifestyle, and fertility not especially related to pesticides. We focused on the most recent pregnancy to avoid dependency issues related to multiple pregnancies on the assumption that the most recent pregnancy would be remembered best. This procedure led to a mixture of first and subsequent pregnancies in the database.

\section{Response}

Only female owners, female partners of owners, and female employees were included in this part of the study. The composition of the original study population and that of the final participants are given in figure 1. Of the 1773 employees and 7105 company owners invited to participate in the study, at least 300 women proved to be ineligible. Completed questionnaires were received from 924 female greenhouse workers and 1058 women in the reference group. The participation rates were $54 \%$ and $49 \%$, respectively, for the greenhouse workers and cleaners selected through the trade union and $50 \%$ and $58 \%$, respectively, of the female greenhouse employees and shopworkers for whom addresses were obtained through the owners. Because the denominator 


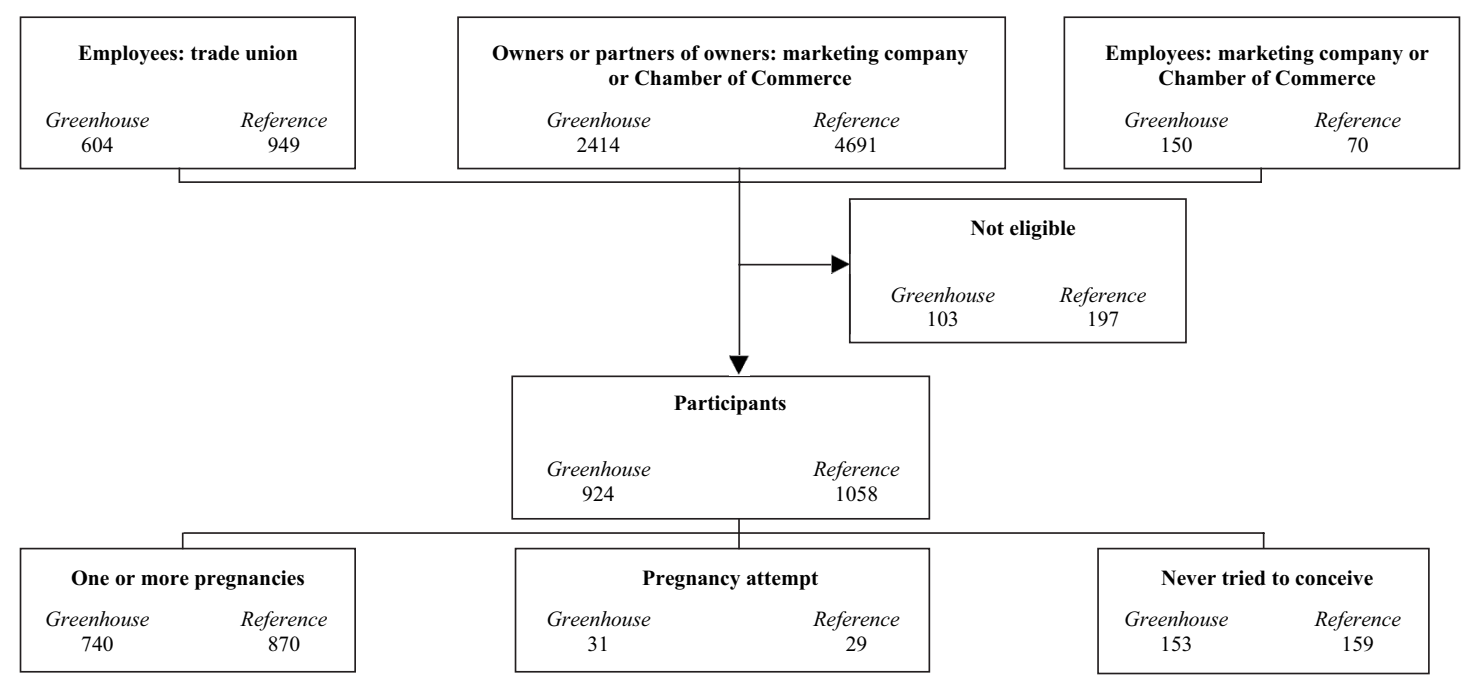

Figure 1. Composition of the study population, final participants, and pregnancy history among the participants. (Not eligible = no longer a member of the trade union, other occupation, or too old)

was unknown, the participation rates for the women approached through the marketing company strategy could not be calculated. At the end of the data collection, a nonresponse study was done. We randomly selected 150 greenhouse workers and 150 cleaners who did not return the questionnaire and who successfully contacted 81 and 70 of them, respectively, by phone. These nonparticipants were asked why they did not respond and whether they had any children. When they did, we asked questions about time to pregnancy and the outcome of the most recent pregnancy. Thirty greenhouse workers and 31 cleaners were willing to answer these questions.

\section{Questionnaires}

The design of the questionnaires was based on the literature and on previous reproductive studies performed by our group (30-32). In the questionnaire, women were asked whether they had ever been pregnant. If so, detailed questions were presented about worktasks (eg, application of pesticides, re-entry activities, and workhours) and lifestyle habits (eg, smoking and coffee and alcohol consumption) of the respondent and her male partner. To approximate the entire time-to-pregnancy period, all of the questions pertained to a period of 6 months before the start of the most recent pregnancy, on the assumption that most women did not change jobs during this period. In addition, questions were asked about time to pregnancy and adverse pregnancy outcomes (eg, spontaneous abortion, preterm delivery, and congenital malformations).

\section{Time to pregnancy}

The primary outcome of this study was time to pregnancy, as a measure for fecundability. The time-to-pregnancy question was phrased as follows: "For the most recent pregnancy, how many months did it take you to get pregnant (counted from the moment you and your partner stopped using contraceptive methods or started trying to get pregnant)?" (32). Only planned pregnancies, not caused by a failure of the birth control method used regardless of pregnancy outcome, were included in the analysis. Time to pregnancy was censured for women with a waiting time longer than 14 months.

\section{Exposure assessment}

To account for job changes and administrative errors in the original population files, we classified all of the participants as "exposed" (greenhouse and other horticulture workers with likely exposure to pesticides), "unexposed" (cleaners, market stall and retail workers, and other workers not exposed to pesticides), or "not working outside the home", based on reported occupation for the 6 months prior to the most recent pregnancy or pregnancy attempt. The work activities reported in the questionnaire, such as re-entry work and specific work with flowers, were also used as indicators for pesticide exposure.

\section{Potential confounding factors}

Potential confounding or effect-modifying factors were recorded for both the men and the women. Smoking habits, alcohol and coffee consumption, use of oral contraception during 1 year preceding the most recent pregnancy, primiparity, and pesticide- exposed partner were used dichotomously in the analyses (yes or no). The educational level was categorized as low (no education and primary, lower vocational, and intermediate vocational education) or high (intermediate secondary, higher secondary, higher vocational, or university education), and the cut-off point for workhours was 32 hours. 
Female age at the start of the most recent waiting time to pregnancy was divided into three groups $(<25,25-$ 35 , or $>35$ years of age), whereas male age was used as a continuous variable in the analyses.

\section{Analyses}

The data from the questionnaires were put into a Microsoft Access database, and statistical analyses were performed using the SPSS 12.0 (SPSS Inc, Chicago, IL, USA) computer program. Associations between time to pregnancy and exposure to pesticides were studied by means of Cox's proportional hazards model. The resulting fecundability ratio (FR) represents the fecundability of the exposed group relative to that of the unexposed group. Initially, crude fecundability ratios with $95 \%$ confidence intervals $(95 \% \mathrm{CI})$ were calculated. Thereafter, multivariable analyses were performed with confounder correction and checks for interaction between pesticide exposure and all of the relevant covariables. We used two criteria to select potential confounding factors, the distribution of the variable among the exposed and unexposed groups and the relation of the potential confounder to time to pregnancy in the unexposed reference group. The complete potential confounder set was then evaluated by reducing the full model with all potential confounders to gain precision without losing validity. Only variables that did not change the fecundability ratio of the pesticide exposure by more than 0.1 upon removal were permanently deleted from the model. A Cox's proportional hazards model was also used to explain time to pregnancy from the following work variables among the female greenhouse workers: function in the company (employee or employer), spraying pesticides (yes or no), cultivating flowers (yes or no), gathering flowers (yes or no), preparing flowers for sale (yes or no), general greenhouse activities without contact with flowers (yes or no), and full-time work ( $>32$ hours; yes or no). A removal probability of $>0.15$ was used in this explorative model.

\section{Biases}

In addition, we investigated the different sources of bias that may occur in studies on time to pregnancy and that were relevant in our study $(33,34)$.

Sterility bias. Time to pregnancy in its strict meaning relates only to periods of unprotected intercourse that end in conception, excluding sterile couples and underrepresenting severely subfertile couples (34). If an exposure causes complete sterility rather than just reducing fecundability, retrospective time-to-pregnancy studies will not detect an adverse effect. Therefore, unsuccessful pregnancy attempts should be taken into account to avoid this bias.
Planning bias. Couples vary in the consistency with which they use birth control. As a result, a large proportion of pregnancies are unwanted or "mistimed" (33). Because these unintended pregnancies were excluded from the analysis of time to pregnancy, bias can arise when planning varies among groups.

Pregnancy recognition bias. This source of bias stems from differential recognition of pregnancy and pregnancy loss (33). Couples that do not recognize an early spontaneous abortion will, in effect, be adding together two (or more) times to pregnancy. This situation reduces their apparent fecundability and usually coincides with a reduced rate of recognized fetal loss.

Wantedness bias. This type of bias may arise from differences in how couples respond to the question of birth control failure (33). To check for this bias, a confirmatory analysis was performed excluding the cycle-one data.

Reproductively unhealthy worker effect. Women who are reproductively healthy tend to reproduce and consequently experience family and societal pressures to leave the workforce or to drop back to part-time employment (33). By contrast, women who are unable to reproduce successfully are more likely to remain in the workforce. The result is that infertile women are more often occupationally exposed. One way to guard against spurious effects due to this type of bias is to stratify the analysis with respect to employment status, comparing exposed full-time workers with other full-time workers and part-time workers to part-time workers. Another strategy is to limit the analyses to women conceiving their first pregnancy. Both strategies were explored in this study.

\section{Results}

From the 1982 initial participants, 372 women who had never been pregnant were dropped. [See figure 1.] All of the other participants, except 65 women for whom the occupation was unknown, were placed in one of the three occupational groups. This procedure resulted in 473 "exposed" greenhouse workers, 679 "unexposed" referents, and 393 women who were not working in the 6 months period prior to the most recent pregnancy. Table 1 summarizes the work activities for the greenhouse workers, further divided into employees $(28.5 \%)$ and owners or partners of owners (71.5\%). The main tasks included cultivating, gathering, and bunching flowers, but no pesticides were sprayed by these female greenhouse workers. Apart from re-entry and packing 
tasks, several nongreenhouse activities were reported, such as office work and cleaning, especially by greenhouse owners and partners of owners. In general, these women seemed to be less involved in actual greenhouse work with a potential for pesticide exposure than greenhouse employees, and most of them worked part-time (32 hours per week or less).

The general characteristics of the final study population are shown in table 2 . Women with unexpected pregnancies $(\mathrm{N}=163)$ or an unknown time-to-pregnancy value for the most recent pregnancy $(\mathrm{N}=67)$ were excluded from the final analyses. The mean age of the women was 29.4 and 28.0 years for the greenhouse workers and referents, respectively, but the proportion of younger women ( $<25$ years of age) was much smaller among the greenhouse workers. The women in the reference group had a slightly lower education and smoked more often than the greenhouse workers, but a smaller proportion of the referents consumed alcohol and coffee and participated in sports. The use of multivitamins or folic acid and oral contraceptives was similar between the two groups. Large differences were found for the proportions of primigravidous women (12.1\% among the greenhouse workers versus $23.9 \%$ among the referents) and the mean number of children (2.6 and 1.9, respectively). In addition, more of the greenhouse workers had part-time employment ( 32 hours per week or less). The male partners of the greenhouse workers were slightly older than their reference counterparts and smoked less often. However, $77 \%$ of them were occupationally exposed to pesticides
Table 1. Different work activities among the groups of greenhouse workers.

\begin{tabular}{|c|c|c|c|c|c|c|}
\hline \multirow[t]{2}{*}{$\begin{array}{l}\text { Work } \\
\text { activities }\end{array}$} & \multicolumn{2}{|c|}{$\begin{array}{c}\text { Greenhouse } \\
\text { workers } \\
(\mathrm{N}=473)^{\mathrm{a}}\end{array}$} & \multicolumn{2}{|c|}{$\begin{array}{l}\text { Greenhouse } \\
\text { employees } \\
(\mathrm{N}=135)^{\text {a }}\end{array}$} & \multicolumn{2}{|c|}{$\begin{array}{l}\text { Greenhouse } \\
\text { owners or } \\
\text { partners of } \\
\text { owners } \\
(\mathrm{N}=338)^{\mathrm{a}}\end{array}$} \\
\hline & N & $\%$ & N & $\%$ & N & $\%$ \\
\hline Cultivating flowers & 265 & 64.8 & 92 & 80.7 & 173 & 58.6 \\
\hline Gathering flowers & 241 & 58.9 & 70 & 61.4 & 171 & 58.0 \\
\hline Preparing flowers for sale & 308 & 75.3 & 67 & 58.8 & 241 & 81.7 \\
\hline $\begin{array}{l}\text { General greenhouse activities } \\
\text { without contact with flowers }\end{array}$ & 95 & 23.2 & 29 & 25.4 & 66 & 22.4 \\
\hline $\begin{array}{l}\text { Other activities (open-ended } \\
\text { question) }\end{array}$ & 242 &.. & 69 & .. & 173 & .. \\
\hline Administrative or office work & 47 & 11.5 & 9 & 7.9 & 38 & 12.9 \\
\hline Canteen work or cleaning & 34 & 8.3 & 5 & 4.4 & 29 & 9.8 \\
\hline Housekeeping & 39 & 9.5 & 5 & 4.4 & 34 & 11.5 \\
\hline Workhours (>32 hours) & 103 & 22.7 & 44 & 33.3 & 59 & 18.3 \\
\hline
\end{tabular}

a No information on worktasks was available for 21 employees and 43 greenhouse owners or partners of owners; information on workhours was missing for 3 employees and 16 greenhouse owners or partners of owners.

versus only $9.9 \%$ of the partners of women in the reference group.

In the crude analysis, the female greenhouse workers seemed to be more fecund than the unexposed reference group ( $\mathrm{FR}_{\text {crude }} 1.18,95 \%$ CI 1.03-1.35) (table 3 ). Correction for age, smoking, and multivitamin use of the mother, as well as for primigravidity, changed the $\mathrm{FR}_{\mathrm{adjusted}}$ to 1.11 (95\% CI $\left.0.96-1.29\right)$. No other confounding or effect-modifying factors were identified.

Table 2. General characteristics of the final study population consisting of women with one or more pregnancies and a time-to-pregnancy value for the most recent pregnancy. ${ }^{\text {a }}$

\begin{tabular}{|c|c|c|c|c|c|c|c|c|}
\hline \multirow[t]{2}{*}{ Characteristics } & \multicolumn{4}{|c|}{ Greenhouse workers (exposed to pesticides) $(\mathrm{N}=398)^{\mathrm{b}}$} & \multicolumn{4}{|c|}{ Reference group (unexposed) $(\mathrm{N}=524)^{b}$} \\
\hline & $\mathrm{N}$ & $\%$ & Mean & SD & $\mathrm{N}$ & $\%$ & Mean & SD \\
\hline Age (years) & .. & $\cdot \cdot$ & 29.4 & 3.3 & .. & . & 28.0 & 4.0 \\
\hline$<25$ years & 45 & 11.9 & .. & .. & 125 & 26.4 & .. & .. \\
\hline 25-35 years & 318 & 83.9 & .. & .. & 331 & 69.8 & .. & .. \\
\hline$>35$ years & 16 & 4.2 & $\cdot \cdot$ & .. & 18 & 3.8 & .. & .. \\
\hline Low educational level & 209 & 52.8 & $\cdot$. & .. & 292 & 56.3 & .. & .. \\
\hline Smoking & 88 & 22.3 &.$\cdot$ & .. & 230 & 44.0 & .. & .. \\
\hline Alcohol consumption & 237 & 59.8 & .. & $\cdot \cdot$ & 237 & 45.3 & $\cdot$. & . \\
\hline Coffee consumption & 331 & 83.6 & $\cdot$. & .. & 411 & 78.6 & .. & .. \\
\hline Sports activities & 236 & 59.4 & $\cdot$. & .. & 233 & 44.6 & .. & .. \\
\hline Body mass index & $\cdot$. & $\cdot \cdot$ & 24.1 & 3.5 & $\cdot$ & · & 24.9 & 4.6 \\
\hline Use of multivitamins or folic acid & 104 & 26.3 & $\cdot$. & .. & 151 & 28.8 & .. & .. \\
\hline Use of oral contraceptives & 249 & 62.7 & .. & .. & 339 & 64.9 & .. & .. \\
\hline Primigravidity & 48 & 12.1 & .. & .. & 125 & 23.9 & $\cdot \cdot$ & . \\
\hline Number of children & $\cdot$ & . & 2.6 & 1.0 & & & 1.9 & 0.8 \\
\hline Workhours $(\leq 32)$ & 305 & 79.0 &.$\cdot$ & .. & 356 & 70.2 & .. & .. \\
\hline
\end{tabular}

a The mean age of the male partners was 33.0 (SD 3.7) years for the greenhouse workers and 31.9 (SD 5.0) years for the reference group; the mean number of male partners who smoked was $141(35.6 \%)$ for the greenhouse workers and $264(50.7 \%)$ for the reference group; the mean number of male partners of those exposed to pesticides was $292(77.0 \%)$ for the greenhouse workers and $50(9.9 \%)$ for the reference group.

b These numbers were reduced by varying numbers of missing values per variable (maximum $4.8 \%$ ). 
The explorative model used to explain time to pregnancy from several work variables among the female greenhouse workers initially showed that being an employee or working full-time ( $>32$ hours/week) was associated with prolonged time to pregnancy (table 3 ). However, when primigravidity was included in the model, only working full-time remained a risk factor for prolonged time to pregnancy (FR 0.78, 95\% CI 0.59-1.01), whereas the decreased fecundability among employees could be explained by primigravidity (FR $0.66,95 \%$ CI 0.44 $0.97)$. The analysis with the primigravidous women only showed that gathering flowers may involve an increased risk of prolonged time to pregnancy (FR $0.46,95 \% \mathrm{CI}$

Table 3. Associations between pesticide exposure and prolonged time to pregnancy for the greenhouse workers versus the referents and the associations between the work variables and time to pregnancy among the greenhouse workers. ( $F R=$ fecundability ratio, $95 \% \mathrm{Cl}=95 \%$ confidence interval)

\begin{tabular}{|c|c|c|c|c|}
\hline $\begin{array}{l}\text { Population and variables } \\
\text { in model }\end{array}$ & $\begin{array}{l}\text { Crude } \\
\text { FR }\end{array}$ & $95 \% \mathrm{Cl}$ & $\begin{array}{l}\text { Adjusted } \\
\text { FR }\end{array}$ & $95 \% \mathrm{Cl}$ \\
\hline \multicolumn{5}{|l|}{ Total study population (N=922) } \\
\hline Greenhouse worker & 1.18 & $1.03-1.35$ & $1.11^{\mathrm{a}}$ & $0.96-1.29$ \\
\hline \multicolumn{5}{|l|}{ Greenhouse workers $(\mathrm{N}=386)$} \\
\hline $\begin{array}{l}\text { Employee } \\
\text { Workhours (>32) }\end{array}$ & $\begin{array}{l}0.81 \\
0.74\end{array}$ & $\begin{array}{l}0.64-1.02 \\
0.57-0.96\end{array}$ & $\begin{array}{l}0.96^{b} \\
0.78^{b}\end{array}$ & $\begin{array}{l}0.73-1.26 \\
0.59-1.01\end{array}$ \\
\hline \multicolumn{5}{|c|}{ Primigravidous greenhouse workers only $(\mathrm{N}=42)$} \\
\hline $\begin{array}{l}\text { Gathering flowers } \\
\text { Preparing flowers for sale }\end{array}$ & $\begin{array}{l}0.46 \\
2.36\end{array}$ & $\begin{array}{l}0.18-1.19 \\
0.86-6.43\end{array}$ & - & \\
\hline
\end{tabular}

$0.18-1.19)$, whereas the women who primarily prepare flowers for sale seemed to be more fecund than other primigravidous greenhouse workers (FR 2.36, 95\% CI 0.86-6.43).

The evaluation of the different sources of bias specific for time-to-pregnancy studies is summarized in table 4 .

Sterility bias. No difference was observed between the greenhouse workers and the referents as regards the number of unsuccessful pregnancy attempts $(4.4 \%$ and $4.2 \%$, respectively); therefore, this type of bias was not present in our data.

Planning bias. Among the greenhouse workers, $10.4 \%$ of the women reported an unintended pregnancy versus $16.8 \%$ of the women in the reference group. This difference of $6.4 \%$ (95\% CI 6.0-6.8) led to a fecundability ratio of 1.09 (95\% CI 0.96-1.23) for the greenhouse workers versus the referents when we included women with unintended pregnancies in the analyses on the assumption of a time to pregnancy of 1 month. Therefore, the crude fecundability ratio of 1.18 seemed to be moderately biased by pregnancy planning differences.

Pregnancy recognition bias. The greenhouse workers reported 3.6\% recognized spontaneous abortions versus $6.0 \%$ for the reference group. This small difference indicates that some of the greenhouse workers may have overestimated their time to pregnancy.

Wantedness bias. The result of a confirmatory analysis without the cycle-one data (crude FR 1.15, 95\% CI

Table 4. Evaluation of different sources of bias specific for time-to-pregnancy studies in our data comparing greenhouse workers with the unexposed reference group. ( $F R=$ fecundability ratio, $95 \% \mathrm{Cl}=95 \%$ confidence interval)

\begin{tabular}{|c|c|c|c|c|c|c|c|}
\hline Type of bias & $\mathrm{N}$ & $\%$ & $\begin{array}{c}\text { Crude } \\
\text { FR }\end{array}$ & $95 \% \mathrm{Cl}$ & $\begin{array}{l}\text { Adjusted } \\
\text { FR }\end{array}$ & $95 \% \mathrm{Cl}$ & $\begin{array}{l}\text { Potential for } \\
\text { bias }\end{array}$ \\
\hline \multicolumn{7}{|l|}{ Sterility bias (no pregnancy achieved) } & No \\
\hline Greenhouse workers & 22 out of 495 & 4.4 & .. & .. & .. & .. & \\
\hline Reference group & 30 out of 709 & 4.2 &.$\cdot$ & .. & .. & .. & \\
\hline \multicolumn{7}{|l|}{ Planning bias (unintended pregnancies) } & Moderate \\
\hline Greenhouse workers & 49 out of 473 & 10.4 &.$\cdot$ & .. & .. &.$\cdot$ & \\
\hline Reference group & 114 out of 679 & 16.8 &.$\cdot$ &.. & .. & .. & \\
\hline \multicolumn{7}{|c|}{ Pregnancy recognition bias (recognized spontaneous abortion) } & Small \\
\hline Greenhouse workers & 17 out of 473 & 3.6 & .. & .. & .. & .. & \\
\hline Reference group & 41 out of 679 & 6.0 & .. & $\cdot \cdot$ & .. & $\cdot \cdot$ & \\
\hline \multicolumn{7}{|l|}{ Wantedness bias } & No \\
\hline Including cycle one & .. & .. & 1.18 & $1.03-1.35$ & .. & .. & \\
\hline Excluding cycle one &.$\cdot$ & .. & 1.15 & $0.99-1.35$ &.$\cdot$ &.. & \\
\hline \multicolumn{7}{|l|}{ Reproductively unhealthy worker effect } & High \\
\hline $\begin{array}{l}\text { Part-time workers } \\
\text { ( } \leq 32 \text { hours or less) }\end{array}$ & 661 &.$\cdot$ & 1.28 & $1.09-1.50$ & $1.18^{a}$ & $0.99-1.41$ & \\
\hline $\begin{array}{l}\text { Full time workers } \\
\text { (>32 hours) }\end{array}$ & 232 & $\cdot \cdot$ & 0.90 & $0.68-1.21$ & $0.89^{b}$ & $0.67-1.19$ & \\
\hline First pregnancy & 173 &.. & 0.92 & $0.63-1.32$ & $0.90^{c}$ & $0.62-1.32$ & \\
\hline
\end{tabular}

a Adjusted for age of mother, maternal smoking, multivitamin use, and primigravidity.

${ }^{\mathrm{b}}$ Adjusted for primigravidity.

${ }^{c}$ Adjusted for maternal smoking. 
0.99-1.35) did not differ from that in the original analysis including the cycle-one data; therefore wantedness bias did not play a role in our study.

Reproductively unhealthy worker effect. The part-time greenhouse workers seemed to be more fecund than the part-time working women in the reference group $\left(\mathrm{FR}_{\text {adjusted }} 1.18,95 \%\right.$ CI 0.99-1.41), whereas the full-time greenhouse workers seemed to have a slightly longer time to pregnancy ( $\left.\mathrm{FR}_{\text {adjusted }} 0.89,95 \% \mathrm{CI} 0.67-1.19\right)$. When the analysis was restricted to the primigravidous women only, the fecundability ratio for the greenhouse workers versus the referents was similar to the one for the full-time workers ( $\mathrm{FR}_{\text {adjusted }} 0.90,95 \%$ CI $\left.0.62-1.32\right)$, but the confidence interval was wider due to the small numbers. These analyses pointed towards a high degree of bias in our original results due to the reproductively unhealthy worker effect.

\section{Discussion}

Initially, the female greenhouse workers appeared to be more fecund than the unexposed reference group in this study. After we investigated different sources of bias, including the reproductively unhealthy worker effect, however, we observed slightly decreased fecundability ratios for the full-time and primigravidous greenhouse workers. When we compared different worktasks among the greenhouse workers only, we found similar but stronger associations between reduced fecundability and full-time work and primigravidity. This analysis also pointed towards an increased risk of prolonged time to pregnancy for primigravidous women involved in gathering flowers. Before these results are discussed further, however, some methodological issues need to be addressed.

The general response rate of our study was low, in particular among market stallholders and retail shopkeepers. This low response may have been due to the selection of owners of small companies or market stalls who were too busy to fill out the questionnaire. Alternatively, our questionnaires could have been labeled as junk mail in large companies. Moreover, the company owners were mostly men, who are known to have a low response rate in reproductive studies (35). This possibility may have caused a low response rate among their female partners as well. As selection for age was not possible for the reference group, a relatively large number of people could also have been too old to see the relevance of a questionnaire on reproductive issues. However, since the study was presented as general research on work and lifestyle habits, not putting any emphasis on pesticide exposure, greenhouse workers with adverse pregnancy outcomes had no more reason to participate than cleaners, market stallholders, or retail shopkeepers with similar problems. This situation strongly reduces the chances of response bias, and the lack of bias was confirmed in our nonresponse study, in which we found a mean time to pregnancy (censored at 14 months) of 3.5 months (SD 4.8) for the greenhouse workers and 3.7 months (SD 4.3) for the reference group among the nonparticipants. These time to pregnancies were lower than the mean time to pregnancies among the participants [4.3 months (SD 4.0) and 4.9 months (SD 4.4), respectively], but similar for the greenhouse workers and the referents.

The choice of the reference group, which consisted of women working as professional cleaners and in shops and market stalls, is an important point of discussion. We chose this reference group for our population of greenhouse workers because of the similar educational level, socioeconomic status, and work conditions (such as standing and carrying loads) apart from pesticide exposure. A literature review did not find any evidence of reduced fertility among the female professional cleaners (36) or the shop workers, and, when we removed cleaners from the reference group, the results of our study remained similar. Moreover, the cleaners participating in this study mainly used standard nonaggressive household detergents. Differences may exist, however, between the partners of shopkeepers and the partners of greenhouse owners. The latter often live on the premises and may partly be housewives who help out in the greenhouse when needed. A tendency towards such a dual role can be found in table 1, which shows that, on the average, greenhouse owners or partners of owners seem to be less involved in actual greenhouse work with a potential for pesticide exposure and they work shorter hours than greenhouse employees. This tendency may have reduced the contrast in pesticide exposure between the female greenhouse workers and the unexposed referents.

In this study, data were collected by means of questionnaires, and, therefore, there was a probability of misclassification for the outcome measure, exposure, and confounder variables. Not everyone in the study was able to produce an adequate time-to-pregnancy value, but, in general, time-to-pregnancy data are considered valid estimates of the waiting time to pregnancy $(34,37)$ and, therefore, lead only to nondifferential misclassification and an underestimation of the fecundability ratio. Concerning exposure, no distinctions could be made for the amount and kinds of pesticides used, as many different pesticides were reported, some of which may not be reproduction-toxic. Moreover, not all greenhouse workers, and in particular partners of owners, may actually have been exposed to relevant concentrations of pesticides. Consequently, the effects of pesticide 
exposure on time to pregnancy may have been underestimated. The major confounders for the relationship between pesticide exposure and time to pregnancy mentioned in the literature were recognized and controlled in our dataset. However, residual confounding due to uncontrolled confounders or imperfect measurement of some confounders that we did control may still have played a role in our study. This possibility may especially hold for the use of oral contraceptives. Because of an unclear formulation in the questionnaire, the women having trouble conceiving did not answer this particular question correctly. Of all of the potential confounders, including pesticide exposure of the male partner, only a few proved to be actual confounders in the different Cox's proportional hazards models.

Several types of bias specific for time-to-pregnancy studies $(33,34)$ were evaluated, and we concluded that sterility bias and wantedness bias did not play a role in our study. Other types of bias mentioned by Weinburg et al (33) were excluded a priori, as we prevented medical intervention bias by censuring time to pregnancy at 14 months and did not expect many women in the Netherlands to change jobs, work habits, or behavior during their waiting time to pregnancy, which would lead to time trend bias and behavior modification bias. The questions on work and lifestyle habits pertained to the period of 6 months before the start of the most recent pregnancy, but only $18.3 \%$ of the greenhouse workers had a time to pregnancy longer than 6 months. Half of these women conceived within 1 year, and only one woman reported a time to pregnancy of more than 5 years, but all of these women worked in greenhouse jobs for the entire time-to-pregnancy period. The mean number of years of work in greenhouses was 15.5 years at the time of the data collection.

In contrast, we observed a small potential for pregnancy recognition bias, which may have biased the fecundability ratio in the direction of decreased fecundability, and a moderate potential for planning bias, which biased the fecundability ratio in the direction of increased fecundability. The evaluation of pregnancy recognition bias, however, may have been hampered by the self-reported nature of spontaneous abortion (38). The largest amount of bias for our data seemed to be caused by the reproductively unhealthy worker effect due to the fact that we studied the most recent pregnancy, which is a mixture of first and higher-order pregnancies. Restricting the analyses to full-time work or primigravidous women only changed the results from $10 \%$ increased fecundability $\left(\mathrm{FR}_{\text {adjusted }} 1.1\right)$ among the female greenhouse workers in the original analysis of all of the most recent pregnancies to $10 \%$ decreased fecundability ( $\left.\mathrm{FR}_{\text {adjusted }} 0.9\right)$ in the "unbiased" analysis, although small numbers led to large confidence intervals that are compatible with no effects on fecundability.
According to Olsen (39), the analysis of first pregnancies only was the most valid, as it avoided pregnancyplanning issues in which past-pregnancy experiences are taken into account. Abell et al (21) found a fecundability ratio comparable with ours for the most recent pregnancies among workers in flower greenhouses versus other union workers in Denmark (FR 1.1, 95\% CI 0.91.4). They also reported fecundability ratios in the same range for first pregnancies only (data not given), which is in contrast to our results. However, a large study of first pregnancies in Colombia (22) reported a decreased fecundability ratio for women working in flower production companies in the same order of magnitude as ours (FR 0.9, 95\% CI 0.8-1.0). Abell et al (21) also performed additional analyses among workers in flower greenhouses and found that spraying pesticides, handling cultures for many hours per week, and not using gloves was related to reduced fecundability. In our study, pesticides were not sprayed by women, and, as a result, no information on glove use was collected. However, among the primigravidous women, an association with prolonged time to pregnancy was observed for gathering flowers, which is usually a daily task involving intensive contact with plants whether or not they have recently been treated with pesticides.

In conclusion, this study may add some evidence for the hypothesis of adverse effects of pesticide exposure on time to pregnancy, but more research is needed to elucidate these effects and provide insight into the worktasks that may expose female greenhouse workers to pesticides.

\section{Acknowledgments}

We are very obliged to the participating trade union, the Chamber of Commerce, and the agricultural marketing company for providing the study sample and to the participants for filling out the questionnaires.

The study was financially supported by the Netherlands Organisation for Scientific Research (grant no 904-63-116).

\section{References}

1. Kavlock RJ, Daston GP, DeRosa C, Fenner-Crisp P, Gray LE, Kaattari S, et al. Research needs for the risk assessment of health and environmental effects of endocrine disruptors: a report of the U.S. EPA-sponsored workshop. Environ Health Perspect. 1996;104 suppl 4:715-40.

2. Crisp TM, Clegg ED, Cooper RL, Wood WP, Anderson DG, Baetcke KP, et al. Environmental endocrine disruption: an effects assessment and analysis. Environ Health Perspect. 
1998;106 suppl 1:11-56.

3. Andersen HR, Vinggaard AM, Rasmussen TH, Gjermandsen IM, Bonefeld-Jorgensen EC. Effects of currently used pesticides in assays for estrogenicity, androgenicity, and aromatase activity in vitro. Toxicol Appl Pharmacol. 2002;179:1-12.

4. Guillette LJ Jr, Gross TS, Masson GR, Matter JM, Percival HF, Woodward AR. Developmental abnormalities of the gonad and abnormal sex hormone concentrations in juvenile alligators from contaminated and control lakes in Florida. Environ Health Perspect. 1994;102:680-8.

5. Stoker TE, Cooper RL, Goldman JM, Andrews JE. Characterization of pregnancy outcome following thiram-induced ovulatory delay in the female rat. Neurotoxicol Teratol. 1996;18:277-82.

6. Nicolopoulou-Stamati P, Pitsos MA. The impact of endocrine disrupters on the female reproductive system. Hum Reprod Update. 2001;7:323-30.

7. McDonald AD, McDonald JC, Armstrong B, Cherry NM, Cote R, Lavoie J, et al. Fetal death and work in pregnancy. Br J Ind Med. 1988;45:148-57.

8. Savitz DA, Whelan EA, Kleckner RC. Self-reported exposure to pesticides and radiation related to pregnancy outcomeresults from National Natality and Fetal Mortality Surveys. Public Health Rep. 1989;104:473-7.

9. Savitz DA, Whelan EA, Kleckner RC. Effect of parents' occupational exposures on risk of stillbirth, preterm delivery, and small-for-gestational-age infants. Am J Epidemiol. 1989;129:1201-18

10. Goulet L, Thériault G. Stillbirth and chemical exposure of pregnant workers. Scand J Work Environ Health. 1991;17:2531.

11. Lin S, Marshall EG, Davidson GK. Potential parental exposure to pesticides and limb reduction defects. Scand J Work Environ Health. 1994;20:166-79.

12. Nurminen T. Maternal pesticide exposure and pregnancy outcome. J Occup Environ Med. 1995;37:935-40.

13. Pastore LM, Hertz-Picciotto I, Beaumont JJ. Risk of stillbirth from occupational and residential exposures. Occup Environ Med. 1997;54:511-8.

14. Savitz DA, Arbuckle T, Kaczor D, Curtis KM. Male pesticide exposure and pregnancy outcome. Am J Epidemiol. 1997;146:1025-36.

15. Arbuckle TE, Lin Z, Mery LS. An exploratory analysis of the effect of pesticide exposure on the risk of spontaneous abortion in an Ontario farm population. Environ Health Perspect. 2001;109:851-7

16. de Cock J, Westveer K, Heederik D, te VE, van Kooij R. Time to pregnancy and occupational exposure to pesticides in fruit growers in The Netherlands. Occup Environ Med. 1994;51:693-9.

17. Larsen SB, Joffe M, Bonde JP. Time to pregnancy and exposure to pesticides in Danish farmers. Occup Environ Med. 1998;55:278-83

18. Thonneau P, Abell A, Larsen SB, Bonde JP, Joffe M, Clavert A, et al. Effects of pesticide exposure on time to pregnancy: results of a multicenter study in France and Denmark. Am J Epidemiol 1999;150:157-163.

19. Petrelli G, Figa-Talamanca I. Reduction in fertility in male greenhouse workers exposed to pesticides. Eur J Epidemiol. 2001;17:675-7.

20. Sallmén M, Liesivuori J, Taskinen H, Lindbohm M-L, Anttila A, Aalto L, et al. Time to pregnancy among the wives of
Finnish greenhouse workers. Scand J Work Environ Health. 2003;29(2):85-93.

21. Abell A, Juul S, Bonde JPE. Time to pregnancy among female greenhouse workers. Scand J Work Environ Health. 2000;26:131-6.

22. Idrovo AJ, Sanin LH, Cole D, Chavarro J, Caceres H, Narvaez $\mathrm{J}$ et al. Time to first pregnancy among women working in agricultural production. Int Arch Occup Environ Health. 2005;78:493-500.

23. Curtis KM, Savitz DA, Weinberg CR, Arbuckle TE. The effect of pesticide exposure on time to pregnancy. Epidemiology. 1999;10:112-7.

24. Fuortes L, Clark MK, Kirchner HL, Smith EM. Association between female infertility and agricultural work history. Am J Ind Med. 1997;31:445-51.

25. Smith EM, Hammonds-Ehlers M, Clark MK, Kirchner HL, Fuortes L. Occupational exposures and risk of female infertility. J Occup Environ Med. 1997;39:138-47.

26. Greenlee AR, Arbuckle TE, Chyou PH. Risk factors for female infertility in an agricultural region. Epidemiology. 2003;14:429-36.

27. Baird DD, Wilcox AJ, Weinberg CR. Use of time to pregnancy to study environmental exposures. Am J Epidemiol. 1986;124:470-80.

28. Baird DD. Using time-to-pregnancy data to study occupational exposures: methodology. Reprod Toxicol. 1988;2:205-7.

29. Tielemans E, Bretveld R, Schinkel J, van Wendel de Joode B, Kromhout H, Gerritsen-Ebben R, et al. Exposure profiles of pesticides among greenhouse workers: implications for epicemiological studies. J Expo Sci Environ Epidemiol. In press.

30. Blatter BM, Roeleveld N, Zielhuis GA, Mullaart RA, Gabreels FJ. Spina bifida and parental occupation. Epidemiology. 1996;7:188-93.

31. Kersemaekers WM, Roeleveld N, Zielhuis GA. Reproductive disorders among hairdressers. Epidemiology. 1997;8:396401.

32. Bonde JPE, Joffe M, Danscher G, Apostoli P, Bisanti L, Giwercman A, et al. Objectives, designs and populations of the European Asclepios study on occupational hazards to male reproductive capability. Scand J Work Environ Health. 1999;25 suppl 1:49-61.

33. Weinberg CR, Baird DD, Wilcox AJ. Sources of bias in studies of time to pregnancy. Stat Med. 1994;13:671-81.

34. Joffe M, Key J, Best N, Keiding N, Scheike T, Jensen TK. Studying time to pregnancy by use of a retrospective design. Am J Epidemiol. 2005;162:115-24.

35. Lindbohm ML. Effects of parental exposure to solvents on pregnancy outcome. J Occup Environ Med. 1995;37:908-14.

36. Florack EI, Zielhuis GA, Rolland R. The influence of occupational physical activity on the menstrual cycle and fecundability. Epidemiology. 1994;5:14-8.

37. Zielhuis GA, Hulscher ME, Florack EI. Validity and reliability of a questionnaire on fecundability. Int J Epidemiol. 1992;21:1151-6.

38. Weinberg CR, Baird DD, Wilcox AJ. Bias in retrospective studies of spontaneous abortion based on the outcome of the most recent pregnancy. Ann N Y Acad Sci. 1994;709:280-6.

39. Olsen J. Options in making use of pregnancy history in planning and analysing studies of reproductive failure. J Epidemiol Community Health. 1994;48:171-4.

Received for publication: 13 June 2005 